\title{
Looking forward to the past: An interdisciplinary discussion on the use of historical analogies and their effects
}

Memory Studies 2017, Vol. 10(3) 274-285 (c) The Author(s) 2017 Reprints and permissions: sagepub.co.uk/journalsPermissions.nav DOI: $10.1177 / 1750698017701609$ journals.sagepub.com/home/mss

(SAGE

\section{Djouaria Ghilani}

Université Libre de Bruxelles, Belgium; Belgian Fund for Scientific Research, Belgium

\section{Olivier Luminet}

Université Catholique de Louvain, Belgium; Belgian Fund for Scientific Research, Belgium

\section{Hans-Peter Erb}

Helmut Schmidt University, Germany

\section{Christine Flassbeck}

Helmut Schmidt University, Germany

\section{Valérie Rosoux}

Université Catholique de Louvain, Belgium; Belgian Fund for Scientific Research, Belgium

\section{Ismee Tames}

Institute for War, Holocaust and Genocide Studies, The Netherlands; Utrecht University, The Netherlands

\section{Olivier Klein}

Université Libre de Bruxelles, Belgium

\begin{abstract}
"This is Munich all over again!": Such comparisons between a present situation and a past one (i.e. a historical analogy) are common in public and political discourses. Historical analogies were used for centuries but have received increased interest in the last 50 years from scholars in political science, history, and psychology. Despite existing interdisciplinary exchanges, it remains difficult to identify the variables involved in the
\end{abstract}

\section{Corresponding author:}

Djouaria Ghilani, Center for Social and Cultural Psychology, Université Libre de Bruxelles, CP I22, Avenue Franklin Roosevelt 50, 1050 Brussels, Belgium.

Email: Djouaria.Ghilani@ulb.ac.be 
phenomenon as different methodologies and conceptualizations are used. Hence, we review part of this voluminous literature and suggest that the various effects related to the use of historical analogies can be grouped under four independent and non-mutually exclusive categories: representing a current situation, defining the roles of current actors, making decisions, and persuading others of a message. We conclude by acknowledging the limits of this current conceptualization and emphasizing its potential as a useful heuristic tool to organize findings in a way that makes them readable across various fields.

\section{Keywords}

historical analogies, politics, psychology, social cognition

\section{Introduction}

The process of drawing parallels between a past event and a current situation is known as a historical analogy and is common in political and public discourses. Known for centuries, the phenomenon has drawn unprecedented interest since 1970s from several disciplines (e.g. political sciences, history, and psychology) and was investigated by a variety of methods (e.g. case studies, archival and discourse analyses, and experimental protocols) in different populations (policymakers, historians, journalists, and lay individuals). After defining the concepts and sketching its intellectual history, we will suggest a typology that accounts for the various effects related to the uses ${ }^{1}$ of historical analogies and illustrate its relevance with both laboratory-based findings and real-life examples.

\section{Definitions}

A historical analogy "signifies an inference that if two or more events separated in time agree in one respect, then they may also agree in another" (Khong, 1992: 6-7). Structurally speaking, analogies are based upon a two-term relationship: a known, past event (i.e. the source) linked to an unfamiliar, current event (i.e. the target; Gentner, 1983), which is seen as similar in some respects to the first.

Given the size and diversity of the literature, it is important to specify that we focus on what cognitive scientists have termed literal or within-domain analogies (Vosniadou and Ortony, 1989), for example, comparing the 9/11 attack in New York to the 1941 attack on Pearl Harbor. These are distinguished from metaphorical or between-domain analogies comparing more semantically distant domains, for example, comparing the 9/11 attack to a move in a chess game (for the political uses of such metaphors, see Ottati et al., 2012). Both political scientists (Khong, 1992; Shimko, 1994) and social psychologists (Kruglanski et al., 2007) have usually adopted the distinction, saving the term historical analogy for the within-domain type of comparisons. Accordingly, our emphasis in this article is on the latter concept, which origins can be traced back to the Classical Greek period.

\section{A brief history of historical analogies}

In the fourth century BC, Aristotle (trans. 1926) already stated that "when two statements are of the same order, but one is more familiar than the other, the former is an "example" (Rhetoric, Book I, chap. 2, section 19). He illustrated this with the case of Dionysius asking for a bodyguard: Since former individuals (e.g. Peisistratus) also requested bodyguards only to "[make] themselves tyrants" once they got them (Aristotle, trans. 1926), one may infer that Dionysius is nursing the 
equally dark intentions of a soon-to-be tyrant. Importantly, Aristotle favorably considered this reliance on the past in political deliberations, seeing it as a useful tool to deal with the inherent uncertainty of novel situations (cf. Ferry, 2013).

A few centuries later, a similar view was expressed in Machiavelli's (1772 [1517]) Discourses, stating,

[...] So that to whoever with diligence examines past events, it is an easy thing to foresee the future in any Republic, and to apply those remedies which had been used by the ancients, or, not finding any of those used, to think of new ones from the similarity of events. (Book I, chap. 39)

Resting his case on a comparison between the popular unrest in the Florentine republic in 1494 and one that took place in ancient Rome, he argued that knowledge of the past could have spared the Florence's people the repetition of similar mistakes.

Yet, the position that history is useful to guide one's decisions was not universally held. For instance, Nietzsche (2010 [1873]) warned that "monumental history deceives through its analogies. It attracts the spirited man to daring acts with its seductive similarities" (section II; emphasis added). Sharing his opinion, twentieth century historian Herbert Butterfield (1951) strongly opposed the idea of applying "lessons" from history ${ }^{2}$ to current situations, arguing that

The dangers of history are liable to become much greater if we imagine that the study of this subject qualifies us to be politicians or provides us with patterns which we can immediately transpose into the context of contemporary politics. (p. 173)

Historian D. Fischer (1970) had a similar view and discussed in length the fallacies that befall historians relying on such analogies in their reasoning, declaring,

[German historian Leopold von] Ranke supported his government in the Franco-Prussian war with the flat assertion that "We are fighting against Louis XIV." This is a classic case of the abuse of historical knowledge. A sophisticated sense of history consists not in the location of analogues such as this but rather in an ability to discriminate between sound analogies and unsound ones. (p. 251)

Hence, both philosophers and historians were long aware of the potential of historical analogies to resolve uncertainty but often advocated caution against the seductive yet misleading sense of clarity they imparted. Around the mid-1970s, the scientific community tackled the phenomenon in an empirical, systematic fashion that differed from the mostly anecdotal, post hoc observations which had prevailed until then.

Overall, these empirical studies echoed earlier assumptions: the predominant view was that history is useful - if well used. Historian Ernest May (1973; Neustadt and May, 1986) documented the reliance on historical analogies (e.g. lessons of the 1930s) by American policymakers in the postWWII era and concluded that they "ordinarily use history badly" (May, 1973: xi). However, according to political scientist Robert Jervis (1976), an information processing perspective would allow to understand such a baffling "misuse" of history - a perspective which emphasized the perceptual and cognitive failings of decision-makers in learning from past cases (e.g. overreliance on salient events).

Around the same time, the effects of non-historical types of analogies in problem-solving were being intensely investigated in cognitive sciences. In typical paradigms, participants were faced with a problem they could solve by adapting the solution of a previously encountered, structurally similar, problem. Yet, Gick and Holyoak (1980) showed that, in the absence of any cues about the potential usefulness of the analogy, individuals usually failed to spontaneously retrieve the correct 
analogical source and to solve the problem at hand. Performance at analogical problem-solving was however improved when participants received a hint about the potential usefulness of a previous solution (Gick and Holyoak, 1980), when they were induced to think about the abstract commonalities between several analogous stories prior to the problem-solving task (Gick and Holyoak, 1983), or when the target and source problem presented obvious surface similarity (Holyoak and Koh, 1987). In particular, the retrieval of analogical sources in memory was greatly facilitated by the existence of a shared surface similarity between the two compared objects (Gentner and Landers, 1985). Such findings are congruent with the seemingly "superficial" analogical use demonstrated by policymakers, exemplified by a tendency "to pick the first analogy that come to mind [...] [to be] impressed by superficial similarities [and to] seldom probe [the analogies] more deeply or widely" (Khong, 1992: 30, 35).

This growing interest for analogical reasoning found echoes in social psychology, with the particularity of focusing on social judgments (Read, 1984) and/or specifically on historical types of analogies (Spellman and Holyoak, 1992). For instance, Gilovich (1981) gave students a description of a fictitious conflict in which a large country attacked its smaller neighbor. The students, assuming the position of a US State Department official, were asked to make recommendations on what the United States should do. Unbeknownst to participants, the description of the conflict had been altered so that, for one group of subjects, it included small, goal-irrelevant details that were meant to remind them of WWII, whereas for a second group, these details were reminiscent of the Vietnam War (a third group received an analogy-neutral description). Results showed that individuals in the WWII group were more favorable to a military intervention in the fictitious conflict compared to those in the Vietnam War group - even though no participants reported finding a similarity between either events. This finding demonstrated not only that exposure to a historical analogy could affect individuals' judgments about a current situation but also that this influence could be implicit and triggered by superficial cues - a result that mirrored the ones found for non-historical analogies. Furthermore, this relationship between analogies and specific attitudes matched with empirical studies conducted in real-life contexts, which showed for instance that individuals who reported perceiving an analogy between WWII and the Gulf War in the 1990s supported more strongly the US military involvement in the latter than those who endorsed the Vietnam War analogy (Schuman and Rieger, 1992).

Together, such findings lent further credit to the psychological view of the phenomenon advanced, in political sciences, by Jervis (1976), Vertzberger (1986), and Khong (1992). The latter was especially influential in formalizing the "cognitive" roles played by analogies in policymaking. Using official reports of meetings, accounts of private conversations and autobiographical writings, he showed how the analogy with the Korean War shaped US' decision-making in Vietnam, for example, by defining the situation as a case of "external aggression" (instead of civil war) while leading President Johnson to avoid a full-scale intervention by fear of drawing China into the conflict (as it had been the case in Korea). Thus, in this "cognitive" view, analogies are functional insofar as they help us interpret contemporary issues - a view shared by subsequent studies, in political sciences (Houghton, 1998), sociology (Rydgren, 2007), and psychology (Perrott et al., 2005; Smeekes et al., 2014).

Yet, the cognitive account of the phenomenon did not convince everyone: some argued that analogies were mainly used for instrumental purposes, thereby allowing policymakers to generate support from political constituencies (e.g. Taylor and Rourke, 1995). Others have also emphasized the discursive nature of this reliance on history (Gibson, 2012; Paris, 2002). Recent work however has usually recognized the non-mutually exclusive character of these views and sought to equally account for both cognitive and more instrumental uses of historical analogies (e.g. Brändström et al., 2004). 
Thus, the idea of political uses of the past is quite ubiquitous across the centuries and has been addressed by several disciplines in the past 50 years. Given the voluminous literature on this topic and its variety across the populations studied (policymakers, historians, journalists, or lay individuals) and the methodologies used, an attempt to integrate its findings proves both necessary (to know where we stand and what is missing) and daunting (because of its size). Below we will suggest one way of accounting for the diverse effects of historical analogies and illustrate its usefulness with both laboratory and real-life examples.

\section{Four categories of effects}

We suggest to group the various effects related to the use of historical analogies under four general categories. These effects are assumed to be both independent (i.e. each can take place on its own) and non-mutually exclusive (i.e. a single analogy can have several effects at the same time) - two features that allow flexibility in this typology.

\section{Representing the current situation}

When faced with an ambiguous, uncertain, complex current situation-the rule in politics (Tetlock, 1998) - a historical analogy can help simplify and organize the incoming information in a coherent manner (Khong, 1992). It does so by shifting the representation of the current situation in ways that are consistent with the representation of the source, effectively anchoring the unfamiliar in the familiar (Gibson, 2012). After the 2004 bombings in Madrid, for instance, the comparison with the 9/11 attacks was widely used by politicians and lay people alike (Truc, 2016). The analogy imposed a measure of order on chaos, allowing Spanish Prime Minister Aznar to describe the Madrid attack at the outset as "having its place in the history of infamy" (Truc, 2016: 58; our translation). This was a direct reference to 9/11, which had itself been described in such terms by analogy to Pearl Harbor-the original "day of infamy" for the United States. By grounding them in the Pearl Harbor analogy, both the 9/11 and Madrid attacks were represented as war events (e.g. rather than criminal ones) and such frames are politically meaningful (Kruglanski et al., 2007).

Moreover, relying on a past case can provide comfort because it signals the current situation is not totally unprecedented (Angström, 2011). Beyond their coping effect, analogies allow one to act as if the two situations compared are identical in critical aspects; hence, offering clues into the unknownan effect akin to analogy-based problem solving in cognitive sciences (e.g. Chan et al., 2012). In the days following the Madrid attacks, the identity of the terrorists was uncertain, though many-including the Spanish government and the United Nations - strongly (and incorrectly) suspected the separatist Basque group ETA. In such an uncertain context, the 9/11 analogy provided novel hypotheses about the perpetrators (e.g. that the ETA collaborated with Al-Qaeda, explaining the similarity in modus operandi between the two attacks) and their motives (e.g. an attack against democracies in both cases; Truc, 2016). This effect epitomizes Fischer's (1970) point that "given our loose pragmatic everyday definition of explanations - i.e., 'making clear, plain, understandable' — analogies are very useful explanatory tools" (p. 243).

Finally, analogies help communicate one's representation (perceptions, feelings) of the situation in an easily understandable way to others - with the intended purpose of communicational fluency rather than persuasiveness (for the latter, see fourth category below). Hence, in the context of the Madrid bombings, the 9/11 analogy allowed to convey in a condensed, yet comprehensive, fashion the turmoil of emotions elicited by current events (Truc, 2016). It appeared to have served the same role after the 2015 attack on the French satirical magazine Charlie Hebdo or the later attacks on 13 
November of the same year, prompting people, for instance, to proclaim that they feel at present very much "the same way they did" after the 9/11 attacks (Ghilani et al., 2015)

Thus, historical analogies achieve here different effects that primarily relate to the representation of a current situation, whether by providing a coherent picture, reducing uncertainty and generating novel hypotheses or helping others understand how the analogizer sees and feels about a present-day issue.

\section{Defining the roles of the actors ${ }^{3}$}

As seen above, part of the effect of analogies is to offer a familiar story-a narrative - that answers several questions about the present (e.g. for terrorist attacks: "Who did what? Why did they do it? What does it mean to me?"; see also Hilton and Liu, this issue). Beyond their descriptive features, such narratives also ascribe social roles to the actors involved (Spellman and Holyoak, 1992), featuring victims, heroes, villains, and their respective relationships (e.g. heroes fight villains). When Aznar described the 2004 Madrid attacks as part of the "history of infamy" (Truc, 2016), he was portraying it as the last installment in a series of events of the class "evil targets democracies." The morality of the actors involved was then doubly stated, the general WWII image evoked the idea of a "Good War" fought for universal values (democracy, freedom), while the specific Pearl Harbor analogy emphasized the right of defending oneself against aggression.

Historical analogies are especially powerful in evoking morality when they involve black-andwhite types of past events (e.g. the Holocaust or colonization; Tierney, 2007). Such morality appraisals are in turn related to specific emotions, such as (collective) shame and guilt, which can be effortlessly channeled through an analogy with the ingroup's past wrongdoings. Accordingly, Rees et al. (2013; Study 2) show how feelings of moral shame regarding the past behavior of ingroup members in Iraq led British participants to entertain more positive attitudes toward present-day, unrelated minorities (Pakistani immigrants) that were perceived as similar to the originally victimized group (Iraqis). In the same line, others found that analogies can affect the representation of social groups (gay or Muslims) even for people holding initially hostile attitudes toward these groups (Perrott et al., 2005; Smeekes et al., 2014).

Yet, given individuals' motivation to perceive themselves and be perceived as moral actors, they are likely to resist analogies that depict them as immoral. During the Vietnam War, one of the reasons that made senior advisers of President Johnson reject the analogy with the French experience at Dien Bien Phu, was that it portrayed the United States as a colonial power crushing a war of liberation (Khong, 1992), thereby questioning the morality of the endeavor. Thus, even for analogies involving seemingly black-and-white past events, their meaning and relevance to the current situation often have to be discursively constructed (Gibson, 2012; Paris, 2002).

Finally, analogies help situate the boundary of group identity, by defining who is part of the ingroup and who is not. The reference to a "European 9/11" that emerged in public discourse after the Madrid attacks and, more recently, after the 2015 Charlie Hebdo attacks, may have involved in some cases an expression of conditional inclusion: European people are those who adhere to a European "civilization" that has to be defended against its enemies (Truc, 2016). The 9/11 analogy reinforces this commonality of values and extends it to all "Western" countries. This partition of the social space is also visible in the analogy with the Crusades that surfaced after the $9 / 11$ attacks and defined the West as engaged in a "clash of civilization" with the Middle-Eastern/Muslim world (Angström, 2011).

In summary, this second category of analogical effects relates more directly to social cognition, social identity, intergroup relations, and collective emotions. It shows that historical analogies can 
affect the perceived (im)morality of actors, elicit (collective) emotions while helping to define and negotiate social identities and their boundaries.

\section{Making decisions}

The third category of effects touches upon future-oriented reasoning: what to do and what will happen next? We will consider in more detail what, in reasoning through analogies, pertains directly to decision-making (rather than to the creation of a mental model of the current situation and its actors). First, historical analogies help prescribe the range of possible alternatives and choose the desired action (Brändström et al., 2004; Khong, 1992). This will depend on what happened in the source event: The past course of action could serve as an anchor (Epley and Gilovich, 2010), constraining the range of readily imagined options and directing one's decisions toward a specific choice.

Moreover, in those conditions, supporting a given decision inherently involves a conditional probability judgment: How likely is it for a favorable outcome to occur if decision $\mathrm{X}$ vs $\mathrm{Y}$ is applied? Analogies can provide such an estimate by pointing to a decision implemented in the past and its perceived consequences (Khong, 1992), before transferring that "lesson" to the current case. Importantly, in order to do so, the analogy must involve a "deeper" level of perceived similarity (see Gentner, 1983), that is, in causal relations between the two events compared (Houghton, 1998; Read, 1984).

After the 2015 Paris attacks, when some invoked the "lessons of 9/11" as an example of the course of actions to be avoided by the French government (e.g. Friedersdorf, 2015), the analogy involved the identification of a causal relation in the analogical source (after the 9/11 attacks, US decision to go to war led to a negative outcome) and its transfer to the target situation (after the Paris attacks, a decision to go to war will also lead to a negative outcome). Note that the first causal claim is supported by an implicit counterfactual reasoning: if the United States had adopted a different decision after 2001, it would have led to a better outcome (see also Bruckmüller et al., this issue, about counterfactuals in causal attribution).

One of the main difficulties in assessing the role of causal factors in real world events relates to their complexity and interrelations (Tetlock, 1998). Yet, in retrospect, events are reconstructed as a set of few, simple and linear relationships that underestimate the role of random factors in producing an outcome (Dawes, 1993) and can result in an inflated sense of inevitability and foreseeability (a hindsight bias; Fischhoff, 1975; see also Klein et al., this issue). Reasoning through historical analogies, in so far as it mobilizes a representation of the past, is inherently affected by our hindsight perspective - a relevant fact for all categories of effects tackled so far. But this is particularly crucial in the case of analogy-based predictions, where the feeling of "understandability" one derives from the past may in turn lead to overestimate one's ability to predict future outcomes (see also Fischer, 1970).

In line with this reasoning, we (Ghilani et al., 2016) recently found that, in some conditions, the perceived likelihood of a negative future outcome following an Iranian Nuclear Deal (e.g. allowing the Iranian to develop nuclear weapons) was affected by the "lesson" of a past event that had been made experimentally available to the participants (i.e. the Versailles Treaty of 1919 vs the Munich Agreement of 1938). Such findings point to the exciting possibility that the increased accessibility of historical analogies may cognitively change the perception of the future itself, making it appear more foreseeable (see also, Rydgren, 2007).

Thus, reasoning through historical analogies has various effects on the decision-making process, such as prescribing a range of policy options, estimating their likelihood of success, and cognitively affecting the perception of possible futures. 


\section{Persuading others}

The last set of effects relates to the use of historical analogies as a way to persuade others of a given message - though several of the functions discussed above can actively be utilized by an analogizer as means of persuasion. Indeed, it may be the case that every analogical use able to affect the analogizers themselves (in their representations, evaluation of actors' roles and prescriptions) is similarly able to affect others. Yet, some have emphasized the distinctiveness of instrumental uses meant solely to argue for and defend one's position, and/or challenge an opponent's (e.g. Paris, 2002; Taylor and Rourke, 1995). In order to account for the variety of findings in the literature, we will consider the persuasive roles of analogies separately, that is, their effectiveness at inducing cognitive and behavioral changes in others - apart from their effect on the analogizer, since it has been shown, for instance, that simply reading an analogical message can change attitudes about a contemporary issue (McCroskey and Combs, 1969).

First, analogies can achieve persuasion by (allegedly) referring to a historical fact, which may appear as "an anchor of validity and truth" (Vertzberger, 1986: 226). The expertise of the analogizer may be crucial for lending credibility to such a claim. For instance, shortly after the 2015 Paris attacks, historian Niall Ferguson compared the latter to the Fall of Rome, as it had also "opened its gates to outsiders [Muslims] who have coveted its wealth without renouncing their ancestral faith" (Ferguson, 2015). This comparison acquires legitimacy mostly from Ferguson's status as a famed historian. Both this perceived expertise and his use of a distant, superficially known source event makes it difficult for a lay audience to challenge the analogy - though not for his fellow colleagues (e.g. Humphries, 2015).

Furthermore, history offers the certainty that a policy or action is not only legitimate with regard to some shared values ("normative legitimacy") but also practically feasible ("cognitive legitimacy"; Vertzberger, 1986): It sets a precedent acknowledging that if something was done once, it is not de facto impossible. Having established that a decision or outcome was possible once in the past, the analogizer can then move on to argue that, however unlikely it appears, the event has an above-than-zero chance of occurring again - then build their argument around avoiding or repeating that action in the present case.

Importantly, the above elements (authority, legitimacy, and feasibility) assume a somewhat "cold" process of argument evaluation from the audience. However, analogies may also affect persuasion through a more peripheral way (Petty and Cacioppo, 1986) that involves eliciting powerful images and affective reactions in the listeners' minds (Khong, 1992; Vertzberger, 1986). For instance, during the Kosovo War in 1999, Clinton's administration advocated for military action by invoking the Holocaust analogy and, particularly, the image of Kosovar refugees fleeing the conflict in train cars - a potent reminder of the Jewish ordeal during WWII (Paris, 2002).

Such persuasive effects are however contingent upon the representation of a past event that the audience possesses and their acceptance of its applicability to the current situation. A case in point is the controversial reference to the Crusades by President G. Bush after the 9/11 attacks (Angström, 2011). Although it is likely that Bush was actually using the word "crusades" in a general sense, it shows that "[i]t is easy to misjudge the emotional effect of an analogy on an unfamiliar audience. Misplaced analogies can backfire and be politically dangerous" (Kruglanski et al., 2007: 104).

In summary, historical analogies achieve persuasive effects by appealing to a sense of "historical truth," the apparent legitimacy and feasibility of an action, or to their emotion-evoking images. It is also possible that, by changing the representation, actor's evaluation and preferred choices of an audience, individuals make use of the first three categories of effects to achieve the last one-persuasion. 


\section{Conclusion}

Historical analogies' long history of thought seems to reflect their equally pervasive presence in our everyday lives, in more or less subtle forms. Although many have warned about their pitfalls, this form of reasoning stubbornly holds on at the edge of every political, public, and scientific discourse. In this article, our aim was to examine the vast literature on historical analogies and organize it in a way that accounts for their various effects on perception, evaluation, and persuasion, which resulted in four categories. Although it seems this typology is better suited to account for explicit uses of historical analogies, the literature (especially in psychological sciences) points to ways in which analogies can achieve each of the four types of effects while remaining implicit (i.e. the analogizer is not aware of the analogy's influence; Bargh, 1992).

For instance, (1) the mental representation of a given issue (marijuana legalization) can subtly shift after being exposed to a historical analogy (alcohol prohibition in the United States), without participants' awareness (Blanchette and Dunbar, 2002). (2) The perception of an actor in a contemporary event can change depending on the dimension of similarity highlighted in an analogous past event (Spellman and Holyoak, 1992). (3) Analogies lead to changes in policy prescriptions even when no similarity between the events compared is perceived by individuals (Gilovich, 1981). Finally, (4) words or expressions that were originally related to a past event can enter the common language and be uttered by a speaker who has no intention of using an analogy, such as the notion of a satellite state (originally used to describe Germany-controlled states before becoming ubiquitous; May, 1973). These "insidious analogies" (Fischer, 1970) would then act as a linguistic framing (Ottati et al., 2012): they may prove persuasive by subconsciously imparting the literal message with an additional subtext directly related to the implied analogical source - though this hypothesis needs to be tested in the future.

Overall, the ability of this typology to account for various - intrapersonal and interpersonal, implicit and explicit - analogical uses discussed in the literature emphasizes its usefulness as a heuristic tool to organize existing findings and to highlight neglected areas of research to explore further. So far, it is but a preliminary attempt at building an interdisciplinary framework regarding the uses of historical analogies; future efforts should be directed at testing more rigorously some of the proposed effects and to specify better the underlying processes that have not been considered here. Yet, by integrating and building upon existing conceptualizations of historical analogies, this typology offers the added advantage of (1) including some uses (e.g. instrumental or rhetorical ones) that tended to be left out from more cognitively oriented accounts (Khong, 1992) and (2) accounting for a wide range of effects described in very different research traditions (political sciences, cognitive sciences, history, and psychology). Finally, this article may also offer a practical tool to decode some rhetorical methods that are not inherently positive or negative: By allowing lay individuals to be involved in the political process, historical analogies - for better or worsehave implications for the democratic process and public debate in general. This might explain the ongoing fascination with the phenomenon across centuries and provides in our view a compelling incentive to research it further in the future.

Thus, as Nietzsche hinted to it, historical analogies have a lot in common with seduction: They can affect the way we make sense of a current situation (and how we interpret ambiguous signs), how we define the "acceptability" of a given partner (while turning others down), which decisions we are tempted to make (and potentially end up regretting), and how successful the seductive attempt proves to be (depending on the receptivity of the partner to our efforts). In the end, even though the potential pitfalls of historical analogies - and seduction alike - are to be heeded, remaining constantly impervious to their charm would make for a perhaps simpler-yet probably quite dull-existence. 


\section{Acknowledgements}

The authors are deeply grateful to Peter Hegarty for his invariably helpful comments on previous drafts of this paper. Many thanks also to William Hirst and Aurélie Van der Haegen for their insights in the course of the writing.

\section{Notes}

1. Following Vertzberger (1986), the term "use" refers here to any "reliance on, and/or employment of, knowledge about past occurrences" (p. 225) with regard to a contemporary situation.

2. Historical analogies usually include drawing (implicit) "lessons"-although learning from the past can also involve other elements (see Levy, 1994).

3. We use the term "actor" in a broad sense, encompassing both the typical actors in psychology and cognitive sciences (individuals, ethnic or social groups) and the ones in political sciences (alliances, nations, and their representatives).

\section{References}

Angström J (2011) Mapping the competing historical analogies of the war on terrorism the bush presidency. International Relations 25(2): 224-242.

Aristotle (trans. 1926) Rhetoric (Book I, trans. JH Freese). Available at: www.perseus.tufts.edu

Bargh JA (1992) Does subliminality matter to social psychology? Awareness of the stimulus versus awareness of its influence. In: Bornstein RF and Pittman TS (eds) Perception without Awareness: Cognitive, Clinical, and Social Perspectives. New York: Guilford Press, pp. 236-255.

Blanchette I and Dunbar K (2002) Representational change and analogy: how analogical inferences alter target representations. Journal of Experimental Psychology: Learning, Memory, and Cognition 28(4): $672-685$.

Brändström A, Bynander F and Hart PT (2004) Governing by looking back: historical analogies and crisis management. Public Administration 82(1): 191-210.

Bruckmüller S, Hegarty P, Teigen KH, et al. (2017) When do past events require explanation? Insights from social psychology. Memory Studies 10(3): 261-273.

Butterfield H (1951) History and Human Relations. London: HarperCollins.

Chan J, Paletz SB and Schunn CD (2012) Analogy as a strategy for supporting complex problem solving under uncertainty. Memory \& Cognition 40(8): 1352-1365.

Dawes RM (1993) Prediction of the future versus an understanding of the past: a basic asymmetry. American Journal of Psychology 106(1): 1-24.

Epley N and Gilovich T (2010) Anchoring unbound. Journal of Consumer Psychology 20(1): 20-24.

Ferguson NC (2015) Paris attacks: fall of Rome should be a warning to the West. The Australian, 16 November. Available at: http://www.theaustralian.com.au/

Ferry V (2013) What is rhetorical certainty? Rhetor 5: 35-43.

Fischer DH (1970) Historian's Fallacies: Toward a Logic of Historical Thought. New York: Harper Torchbooks.

Fischhoff B (1975) Hindsight is not equal to foresight: the effect of outcome knowledge on judgment under uncertainty. Journal of Experimental Psychology: Human Perception and Performance 1(3): 288-299.

Friedersdorf C (2015) Paris and the lessons of the 9/11. The Atlantic. Available at: http://www.theatlantic. com/international/

Gentner D (1983) Structure-mapping: a theoretical framework for analogy. Cognitive Science 7(2): 155-170. Gentner D and Landers R (1985). Analogical reminding: a good match is hard to find. In IEEE 1985 proceedings of the International Conference on Cybernetics and Society. New York: Institute of Electrical and Electronics Engineers, pp. 607-613.

Ghilani D, Luminet O and Klein O (2016). When the past predicts the future: The importance of causal similarity in historical-analogical reasoning. In: Transfer of Knowledge Conference: Communication at the ESCON (ESCON), Lisbon, August. 
Ghilani D, Luminet O, Ernst-Vintila A, et al. (2015) Investigating the Emotional, Attitudinal and Demographic Correlates of Historical Analogizing in the Context of the Charlie Hebdo and 13th November Terrorist Attacks in France. Manuscript in preparation.

Gibson S (2012) History in action: the construction of historical analogies in televised debates concerning the Iraq war. Papers on Social Representations 21(2): 1-35.

Gick ML and Holyoak KJ (1980) Analogical problem solving. Cognitive Psychology 12(3): 306-355.

Gick ML and Holyoak KJ (1983) Schema induction and analogical transfer. Cognitive Psychology 15(1): $1-38$.

Gilovich T (1981) Seeing the past in the present: the effect of associations to familiar events on judgments and decisions. Journal of Personality and Social Psychology 40(5): 797-808.

Hilton D and Liu J (2017) History as a narrative of the people: from function to structure and content. Memory Studies 10(3): 297-309.

Holyoak KJ and Koh K (1987) Surface and structural similarity in analogical transfer. Memory \& Cognition 15(4): 332-340.

Houghton DP (1998) Historical analogies and the cognitive dimension of domestic policymaking. Political Psychology 19(2): 279-303.

Humphries M (2015) Niall Ferguson slammed for saying the West is in danger of falling like the Roman Empire. Available at: http://historynewsnetwork.org

Jervis R (1976) Perception and Misperception in International Politics. Princeton, NJ: Princeton University Press.

Khong YF (1992) Analogies at War: Korea, Munich, Dien Bien Phu, and the Vietnam Decisions of 1965. Princeton, NJ: Princeton University Press.

Klein O, Hegarty P and Fischhoff B (2017) Hindsight 40 years on: An interview with Baruch Fischhoff. Memory Studies 10(3): 249-260.

Kruglanski AW, Crenshaw M, Post JM, et al. (2007) What should this fight be called? Metaphors of counterterrorism and their implications. Psychological Science in the Public Interest 8(3): 97-133.

Levy JS (1994) Learning and foreign policy: sweeping a conceptual minefield. International Organization 48(2): 279-312.

McCroskey JC and Combs WH (1969) The effects of the use of analogy on attitude change and source credibility. Journal of Communication 19(4): 333-339.

Machiavelli N (1772 [1517]). Discourses upon the first ten (books) of Titus Livy (Book I, trans. H Neville). Available at: http://www.constitution.org

May ER (1973) "Lessons" of the past: The Use and Misuse of History in American Foreign Policy. New York: Oxford University Press.

Neustadt RE and May ER (1986) Thinking in Time: The Uses of History for Decision Makers. New York: The Free Press.

Nietzsche F (2010 [1873]). On the use and abuse of history for life (trans. IC Johnston). Available at: http:// records.viu.ca/ johnstoi/nietzsche/history.htm

Ottati VC, Renström RA and Price E (2012) The metaphorical framing model: political communication and public opinion. In: Landau MJ, Meier BP, Robinson MD, et al. (eds) The Power of Metaphor: Examining Its Influence on Social Life. Washington, DC: American Psychological Association, pp. 179-202.

Paris R (2002) Kosovo and the metaphor war. Political Science Quarterly 117(3): 423-450.

Perrott DA, Gentner D and Bodenhausen GV (2005) Resistance is futile: the unwitting insertion of analogical inferences in memory. Psychonomic Bulletin \& Review 12(4): 696-702.

Petty RE and Cacioppo JT (1986) The elaboration likelihood model of persuasion. Advances in Experimental Social Psychology 19: 123-205.

Read SJ (1984) Analogical reasoning in social judgment: the importance of causal theories. Journal of Personality and Social Psychology 46(1): 14-25.

Rees JH, Allpress JA and Brown R (2013) Nie Wieder: group-based emotions for in-group wrongdoing affect attitudes toward unrelated minorities. Political Psychology 34(3): 387-407.

Rydgren J (2007) The power of the past: a contribution to a cognitive sociology of ethnic conflict. Sociological Theory 25(3): 225-244. 
Schuman H and Rieger C (1992) Historical analogies, generational effects, and attitudes toward war. American Sociological Review 57: 315-326.

Shimko KL (1994) Metaphors and foreign policy decision making. Political Psychology 15: 655-671.

Smeekes A, Van Acker K, Verkuyten M, et al. (2014) The legacy of Nazism: historical analogies and support for the far right. Social Influence 9(4): 300-317.

Spellman BA and Holyoak KJ (1992) If Saddam is Hitler then who is George Bush? Analogical mapping between systems of social roles. Journal of Personality and Social Psychology 62(6): 913-933.

Taylor AJ and Rourke JT (1995) Historical analogies in the Congressional foreign policy process. Journal of Politics 57(2): 460-468.

Tetlock PE (1998) Social psychology and world politics. In: Fiske S, Gilbert D and Lindzey G (eds) Handbook of Social Psychology. 4th ed., Vol. 2. New York: McGraw-Hill, pp. 868-912.

Tierney D (2007) "Pearl harbor in reverse": moral analogies in the Cuban missile crisis. Journal of Cold War Studies 9(3): 49-77.

Truc G (2016) Sidérations. Une sociologie des attentats Paris: Presses Universitaires de France.

Vertzberger YY (1986) Foreign policy decisionmakers as practical-intuitive historians: applied history and its shortcomings. International Studies Quarterly 30(2): 223-247.

Vosniadou S and Ortony A (1989) Similarity and Analogical Reasoning. Cambridge: Cambridge University Press.

\section{Author biographies}

Djouaria Ghilani is a PhD student at the Université Libre de Bruxelles. Her research focuses on the effects of historical analogies on judgments and the influence of cognitive-emotional factors in the process of learning from the past.

Olivier Luminet is a professor at the Université Catholique de Louvain and Research Director at the Belgian Fund for Scientific Research. One aspect of his research examines the effects of emotions on individual and collective memories.

Hans-Peter Erb is a full professor and Chair of the Social Psychology Department at the Helmut-SchmidtUniversity, Hamburg. His research interests include human judgment and social influence phenomena.

Christine Flassbeck works as a Post Doc at the Helmut-Schmidt-University, Hamburg. Her research interests include sound symbolic effects on judgments and behavior, persuasion mechanisms, stereotypes, and analogical reasoning.

Valérie Rosoux is a professor at the Université Catholique de Louvain and Senior Research Associate at the Belgian Science Foundation. Her publications focus on memory and international relations.

Ismee Tames is Research Director at NIOD, Institute for War, Holocaust and Genocide Studies and Arq/ Stichting 1940-1945 Professor at Utrecht University. Her research focus is on the experience and effects of war and mass violence on societies.

Olivier Klein teaches social psychology at the Université Libre de Bruxelles. His research interests include collective memory and sexual objectification. 